\title{
Analysis on China's Urban-Rural Integration: The Perspective of Path-Dependence
}

\author{
Xiaoqun Yang \\ School of Public Administration and Emergency Management, Jinan University, Guangzhou, China \\ Email: 454203792@qq.com
}

Received 13 January 2016; accepted 22 February 2016; published 25 February 2016

Copyright (C) 2016 by authors and Scientific Research Publishing Inc.

This work is licensed under the Creative Commons Attribution International License (CC BY). http://creativecommons.org/licenses/by/4.0/

c) (i) Open Access

\begin{abstract}
With the development of the economy and society, to a certain extent, the development of the rural and the urban areas will integrate as the economic trend. The urban-rural dual structure in China has been mitigated in recent years, however, overall there are still a lot of differences between the rural and urban areas and the gap between them cannot be ignored. The integrated development of rural and urban areas is at a low level and it is confronted with the negative effects of path-dependence. They are some factors now constraining the urban-rural integration, like the governance concept of separated administration in the urban and the rural areas, the impact of the choice of the initial institution and the negative impact of the urban and the rural subject behavior. Therefore, in order to break the path-dependence of urban-rural integration, innovation is needed in the concept of governance, institutional framework, motivation system, cooperation mechanism and so on.
\end{abstract}

\section{Keywords}

Urban-Rural Integration, Institutional Transition, Path-Dependence, Institutional Innovation

\section{Introduction}

Since the reform and opening up, the economy in China has been developing rapidly, but the urban-rural dual structure from the planned economy has not been changed fundamentally, which has become the systematic contradiction in the sound development of China's economy. The urban-rural dual structure is a series of concepts to maintain the dual economic form of the modern urban sectors and the rural traditional ones, and the separated dual social systems between the rural and urban societies [1]. Currently, to improve the socialist market economy, enhance urbanization, develop the agricultural production, increase farmers' income and narrow the income gap between the urban and the rural areas, it is necessary to reform the urban-rural dual systems [2]. Im- 
proving the level of integration of rural and urban areas will contribute to deepening the reform comprehensively, promoting social justice and equity, and achieving sustainable development in China.

Though the urban-rural dual structure in China has been mitigated in recent years, overall there are still a lot of differences between the urban and the rural areas. The urban-rural integration is at a low level, which is a plain fact and can be seen in many aspects, for example, the urban and the rural residents' income gap, different social security systems and the inequality in the distribution of public resources between the urban and the rural areas. As it can be seen from Table 1, although the ratio of the residents' income between rural and urban areas has narrowed slightly in recent years, the urban residents' income keeps being three times as much as that in the rural areas, and the disparity of the absolute income has been widening. In fact, the change from urban-rural dual structure to integration is the process of institutional transition, and the path-dependence has been slowing down the progress of urban-rural integration. Thus, it is very important to promote the urban-rural integration by innovating the institutions, reforming the urban-rural dual structure and breaking the path-dependence.

\section{Literature Review}

Urban-rural integration is a comprehensive issue, involving many fields like economy, public services, and urban planning. Most of the previous researches mainly analyze and discuss its meaning, impetus mechanism, developing paths, the obstacles, implementation patterns and evaluation systems, etc. Zhen Feng, from the perspective of planning, thinks that urban-rural integration was embodied in the integration of politics, economy, culture, ecology and population [3]. Hong Yinxing and Chen Wen hold the view that urban-rural integration includes institutional integration, urbanization, the integration of industrial structure, agricultural enterprization and farmers' transformation into urban inhabitants [4]. Gu Yikang and Shao Feng view that urban-rural integration is to change the development strategy of the urban-rural gap under the planned economic system, and to establish a new pattern of equal status, openness and interoperability and mutual promotion and progress [5]. Liu Hongmei and Zhang Zhongjie analyze the positive and negative impact of urban-rural integration by building a spacetime and gravity model of the factors that affected the urban-rural integration in China [6].

There are also some documents on this issue from the perspective of institution, but they mainly focus on the institution itself while few of them analyze this issue by means of the theory of institutional transition. Chen Xuehua and Zhao Hongjiang consider that the urban-rural integration in China, in essential, is a compulsive institutional innovation led by the government under the urban-rural dual structure [7]. Zhu Zhiping points out that the evolution of urban-rural dual structure is a coefficient result of the mandatory and the induced institutional transition; therefore, the shackles of the urban-rural dual structure can be broken only by promoting a balanced and

Table 1. Per capita income of urban and rural residents.

\begin{tabular}{lcccc}
\hline Year & $\begin{array}{c}\text { Per Capital Annual Disposable Income of } \\
\text { Urban Households (yuan) }\end{array}$ & $\begin{array}{c}\text { Per Capital Annual Net Income of Rural } \\
\text { Households (yuan) }\end{array}$ & $\begin{array}{c}\text { Absolute Income Gap } \\
\text { Urban/Rural }\end{array}$ & $\begin{array}{c}\text { Income Ratio } \\
\text { Urban/Rural }\end{array}$ \\
\hline 1978 & 343.4 & 133.6 & 209.8 & 2.57 \\
1980 & 477.6 & 191.3 & 286.3 & 2.50 \\
1985 & 739.1 & 397.6 & 341.5 & 1.86 \\
1990 & 1510.2 & 686.3 & 823.9 & 2.20 \\
1995 & 4283.0 & 1577.7 & 2705.3 & 2.71 \\
2000 & 6280.0 & 2253.4 & 4026.6 & 2.79 \\
2005 & 10493.0 & 3254.9 & 7238.1 & 3.22 \\
2010 & 19109.4 & 5919.0 & 13190.4 & 3.23 \\
2011 & 21809.8 & 6977.3 & 14832.5 & 3.13 \\
2012 & 24564.7 & 7916.6 & 16648.1 & 3.10 \\
2013 & 26955.1 & 8895.9 & 18059.2 & 3.03 \\
\hline
\end{tabular}

Source: National Bureau of Statics. URL (last checked 2 January 2016), http://www.stats.gov.cn/tjsj/ndsj/2015/indexch.htm. 
coordinated development between urban and rural areas and the institutional innovation of urban-rural integration [8].

From the above we can see that some scholars have done a lot of useful exploration of the urban-rural integration and their research is quite comprehensive, but few of them have analyzed this issue from the perspective of the institutional transition and most theoretical explanation of this issue in the academic world is still quite weak [9]. This article, with the help of the theory of path-dependence, views that the urban-rural integration in China is a process of institutional transition and the path-dependence phenomenon is the main cause that accounts for the slowly developing integration. Therefore, breaking the path-dependence and forming institutional innovation will effectively promote the process of urban-rural integration in China.

\section{The Theory of Path-Dependence}

The theory of path-dependence was firstly used in institutional transition analysis by North. He views that the four self-reinforcing mechanism in path-dependence, i.e. the initial cost, learning effects, coordination effects of the institution and adaptive expectations, can be applied to the institutional transition. That is to say, the increasing returns also exist in the process of institutional transition. "Under the circumstances of increasing returns, the institution plays a very important role” [10]. Firstly, the initial cost refers to the capital that invested when designing and setting up an institution. Secondly, learning effect refers to how the behavior subjects of the institution know about, understand and recognize the institution and consequently abide by the rules in the institution. Thirdly, coordination effects of the institution, namely under the various rules of the institution, the formation of an institution will encourage the behavior subject to invest more on the institution, proceed the government and other organizations to generate some new formal and informal institutions, with which to remedy and coordinate this institution to play a part, and then form an institutional network. Fourthly, the adaptive expectations of an institution mean that people are able to predict the future profit in the institution and reduce the uncertainty and risks; thus they will understand and accept the institution, providing some legal foundations for the institution. These four mechanisms mentioned above contributed to the "increasing returns" during the transition of the institution and then made the institution develop into the given path. That was how the "path-dependence” came into being [11].

\section{Analysis of the Path-Dependence in Urban-Rural Integration}

For a long time, the difference of the development between the city and the countryside in China is mainly reflected on the different institutional arrangement, which can be found in fourteen aspects, such as the household registration institution, the labor protection system, personnel system, endowment insurance system, of which the household registration institution is at the core [12]. Hence the urban-rural integration in China is a typical institutional problem. At present, the promotion of urban-rural integration has been slowed down because of the impact of the urban-rural dual structure left by the planned economy. Nowadays the promotion of the urban-rural integration is to eliminate the urban-rural split institutional barriers, administrative barriers, policy barriers, etc; meanwhile, is to promote the equalization of basic public service in the city and the countryside, optimize the configuration of public resources and establish urban-rural integrated institutional arrangements of a unified market. Essentially, it is a process of institutional transition. North believes that once the institutional arrangements are on a certain path, it will develop path-dependence as long as there exist increasing returns to strengthen this mechanism [10]. First of all, among the existing urban-rural development mechanisms and patterns, it usually exists a self-reinforcing mechanism of increasing returns, which supplies the implement of urban-oriented policy and the "industrial first" developing strategies, especially at the beginning stage meaning the initial conditions with a powerful institutional inertia, causing the urban-rural development patterns to follow the initial path and the established direction. Under the urban-oriented and "industry first" policy, the countryside and agriculture sacrifice their own interests for the city and the industry and provide them with a lot of money. On the other hand, the concepts play an important role in the institutional transition in the region. They are the ability of cognizance and the cultural traditions people have nowadays, which will make a difference when people design and improve the institution. Traditionally, the urban and the rural areas have been in a state of separation; as a result, the original villages are autonomous and closed. After the founding of new China, the urban-rural dual institution and urban-oriented and "industry first" policy lasted and strengthen the urban-rural separated state, and form the dual mechanism. The concept of urban-rural integration has not yet lay a foundation in 
people's mind. Finally, the urban-rural integration is confronted with many complex problems, like the household registration institution, dual land ownership, the allocation of public resources and the public service system; besides, it is faced with the uncertainty of profits and governments at all levels have been maintaining the current development patterns or slowing down the progress in order to avoid the uncertainty and instability that may appear. The current urban-rural development patterns face many problems, such as the serious unbalanced allocation of public resources, the huge difference of public service and the deficiency of guarantee in farmers' development right, which is restricting the progress of China's modernization. Therefore, we can say that the urban-rural integration itself is a process of institutional transition. The problems of China's development in the rural and urban areas, that is, the separation of city and countryside, the unbalanced allocation of public resources and the absence of public service in rural areas, etc, are the result of the negative path-dependence.

\section{The Predicament of the Path-Dependence of China's Urban-Rural Integration}

\subsection{The Impact of the Concept of Separated Administration in Urban and Rural Areas}

The idea, or ideology, has a deep impact on the behavior selection of the subject of the institutional transition, and then plays an important part in the process of institutional transition. Under some certain historical conditions and a certain institutional environment, the established concepts and thinking set take shape and deeply influence the social behavior and the institutional transition. Under the established social practice and thinking set, people develop their understanding and recognition of the existing institutional framework, which affect their understanding and choices of the new institution.

The dual institution mechanism with the household registration institution at the core which was established in China since 1950's, has broken the contact and interaction of the population, financial and other aspects between the city and the countryside for a long time. Though most of these institutions, such as the household registration, have been eliminated or have been weakening as to provide powerful support for the urban-rural integration. However, the differences in rights that attached to the household registration cannot be solved immediately. Besides, the dual household registration institution has lasted for many decades, and the public and the government still have a thinking set of the separated administration in urban and rural areas towards this policy. In addition, from the governance practice of different areas we can see that the separated administration in the urban and the rural areas is ingrained, and there are several reasons account for it. Firstly, during the thousands years of China's traditional society, the city and the countryside have been in the state of separation. Secondly, under the dual mechanism established in the planned economic era, China has been implement the policy of urban-rural separation and "city and industry first", neglecting the policy guidance for the rural development. The countryside and agriculture stand on the edge of the nation-building for a long time, which strengthen the concept of separated administration in the urban and the rural areas. Thirdly, after the reform and opening up, the establishment of the dual land ownership clearly divided the land into state-owned land and collective land. The property rights of the collective land were severely restricted, forming a concept that city is built on the stateowned land while countryside on the collective land. Therefore, the progress of urban-rural integration is slow and hard.

\subsection{The Impact of the Initial Institution Choice}

The path-dependence theory considers that an institution, once established as an initial one, will affect the following institutional selection and its transition. "That is to say, firstly, the initial selection of the institution will provide and strengthen the currently existing institution's stimulation and inertia because it is more convenient to go along the existing institutional changing path and the established direction than to find a new way; secondly, once an institution is established, it will appear some pressure groups of vested interests in the existing institution. They try their best to consolidate the existing institution and discourage further reform even if the new institution is more efficient than the existing one" [13]. This shows that the design and selection of the initial institution has a great influence on the institutional transition.

At the beginning of the founding of the new China, when confronting with a backward economic society and complex international surroundings, the Chinese government implemented an economic development strategy, that is, to give priority to the development of heavy industry, and establish a highly centralized planned economic institution. Gradually the Chinese government set up the urban-rural dual institution and mechanism which is at the core of unified purchase and marketing, the people's commune, and household registration insti- 
tution. Today, the unified purchase and marketing as well as the people's commune has become a history, but a lot of institutions, such as the present household registration institution and the binary land market, still remain a separated state between the city and the countryside. For example, the state-owned land in cities can be transferred in the land market directly while the rural collective land should be converted into state-owned land through being expropriated firstly by the government before entering the land market. It exists a huge rent space in the transition between these two kinds of land. The compensation that farmers get from the land acquisition is far lower than the price of land transfer. That is to say, the farmers get a little compensation and quit the land value-added process, meaning that they suffer an interest loss. "The industrialization and urbanization in China is established based on the unbalanced regional development. Although most of the dual institutions established in the late 1950's have been eliminated, the long-term effect of the urban-rural dual structure still exists because basically, the land as a spatial carrier of various economic phenomena still exists dual system” [9]. Furthermore, the urban-rural duality is not only an institutional problem, but an institutional network involved the systems like household, financial, land, etc. It results in the high cost of exiting from these systems, generally, it gets into a "locked" state. The development of urban-rural integration in China from the urban-rural duality is greatly influenced by the past institutional arrangements.

\subsection{The Impact of the Urban-Rural Subject Behaviors}

The urban-rural integration involves governments at all aspects, like the urban residents, farmers and varieties of social organizations, the development of which is affected by the relevant subject behaviors. In order to promote the process, especially it needs the central governments and the local ones to cooperate with each other and reform from different levels. The existence of the current behavior subjects is not conductive to the urban-rural integrated behavior, such as the governments' absence in rural public services and farmers' lack of ability to express their demand for public goods. Over the years, the central government has been implementing government-led mechanism of the public goods in the city, where the quantity and quality of the public goods are better than those in the countryside. On the contrary, for a long time the rural areas cannot get the financial support form the nation but to take the way of self-sufficiency at their own expense, moreover, they have to undertake part of the money of the public goods in the city. However, the expression mechanism from bottom to top of the demand for public goods fails to set up. The supply of public goods in the rural is not determined by the needs of the farmers in the area but provided rigidly by the town government and the governments of higher level. The town government is tired of coping with the upgrade for numerous items specified by the governments of higher level and accomplishing tasks to reach the standard, as a result, it has no time to consider the needs of the farmers [14]. Furthermore, owing to the dual household registration system, there are many differences of rights in many respects, such as the separation of the urban and the rural populations, the medical treatment attached to the system of household registration, social security and education. Under the dual institutional network, the central government can only stride forward in increasing the transfer payment of the rural public service in advance, but the pace of the institutional reform is slow because it involves lots of interests and public problems which cover the whole nation and should be considered carefully. For example, to reform the household registration system needs to consider the capacity of the city, and to reform the dual land market involves a series of complex problems like the confirmation of land right. That is easy to see, over a period of time in the past, the progress of the urban-rural integration is slow.

On the other hand, China is in the stage of rapid urbanization, and the city expansion requires a lot of land. Under the dual land ownership, the government collects the collective construction land in large quantities because there are three aspects of benefits that can be expected. Firstly, the collect collective land to meet the need of urban construction that is under the condition of rapid urbanization. Secondly, through transforming the collective construction land into state-owned land, the land is able to be transformed into industrial land for higher taxes and profit of GDP. Thirdly, under the current taxation system, the local governments' source of revenue is limited while the land-transferring fees are stable and reliable for the local government. This is the phenomenon of land finance we called. In addition, the substance of the separated administration in the urban and the rural areas means that the local government only pays attention to the urban development while ignores, or discriminate the rural development. The local government's financial investment in the city is much higher than that in the countryside, because it is easier to get short-term revenue. A very important reference standard to a local governor's promotion is the GDP growth rate. There are too much historical debts in rural development so it is hard to change the backward situation in a short time while the predictable benefit of developing the rural is far 
below developing the urban. Therefore, the local officials must be lack of motivation to substantially promote the urban-rural integration.

\section{The Way to Break the Path-Dependence in China's Urban-Rural Integration}

\subsection{Innovation of Governance Concept}

The government, as the designer and supplier of the formal institution, should have a coordinated integrated concept of the development in the urban and the rural areas. The coordination between the urban and the rural areas and the urban-rural integration have been stressed in the $16^{\text {th }}, 17^{\text {th }}$, and $18^{\text {th }} \mathrm{CPC}$ National Congress, which shows that the CPC central committee and the central government have taken the urban-rural integration as a key point of its decision-making. Now, the local governments ought to break the governance thinking of the separated administration in the urban and the rural areas, and establish a new concept of urban-rural integration and coordination. To expand the perspective of urban-rural integration, it should be stressed not only from the perspective of solving the issues of agriculture, but also from the perspective of releasing the potential of economic growth [15]. Li Yining thinks that the successful exploration of the socialism is with Chinese characteristics and the market economy institution starts with an ideological liberation movement and then breaks the dual institution of the separated administration in the urban and the rural areas, forming the new pattern of urban-rural integration. Meanwhile, it is necessary to further emancipate the mind and seek the truth from facts [16]. Therefore, only by getting rid of the local governments' narrow-minded concept in the urban-rural construction development can China's urban-rural integration jump out of the locked state of the past institution.

\subsection{Innovation of the Institutional Framework}

It is a national problem from the urban-rural dual structure to the urban-rural integration. The central government plays an irreplaceable part in this process and the innovation of the institution and mechanism at the level of the central government should strengthen the top-level design and break the path lock-in. The first step is to build the fundamental of laws for the development of the urban-rural integration. The central government ought to promote the amendment of laws, introduce policies, build an unified land market between the urban and the rural, make the collective construction land and the urban one to enter the market at the same price and right, give property the right to the transfer and rental of the collective construction land, and guarantee the rural farmers' right to share the land increment profit. What's more, the central government should reform the household registration policy, stripe the differences of right attached to the household registration institution and provide conditions for the free flow of human resources between the urban and the rural areas. In addition, the central government should strengthen the authorized strength of urban-rural unified planning, bring the rural into the urban unified planning, strengthen the infrastructure construction and improve the living conditions in the rural areas. Moreover, improving the connection convenience and enhancing the communications between the urban and the rural areas is so meaningful to enhance the interdependence between the urban and the rural areas. The farmers and urban residents should be brought into a unified government public service system and guarantee the farmers to have the equal right to share the public services. All in all, the government should implement an urban-rural unified social security system and strengthen the construction of rural public service, and sequentially promote the construction of urban-rural integration.

\subsection{Innovation of the Motivation System}

The institution, to some extent, is an immobilized arrangement of the distribution of interests. The institutional transition is to reform the old systems and to create the new ones, which is bound to change the existing patterns of interests. Those who stick up for the old systems are the ones of vested interest, with whom the existing system accord. At present, the one that lack of substantial motivation to promote the urban-rural integration is the local governments, which is closely related with the path-dependence formed during the development of urban-rural integration. At first, the current financial and taxation system should be reformed. It is time to make rational adjustment of the financial and administrative power of the central and the local governments and give the local governments more financial power, for making the financial capacity to match the financial power of the local governments and gradually get rid of the current land financial phenomenon which is getting worse. It is also essential to change the situation that town finance is attached to the county finance, to implement a coun- 
ty-town integrated financial system arranged in a unified way by the county governments, and to coordinate the supply of public goods in the urban and the rural areas. Secondly, the assessment and promotion mechanism based only on the GDP in the local governments should be changed. Instead, to establish assessment indicators for the urban-rural coordinated development and legislation to restrain the irrational phenomenon of "one leader, one development strategy", meanwhile, it is meaningful to eliminate the foundation of institution that both the local governments and officials seek short-termed interests in the urban construction so as to highlight their achievement. Finally, it is time to establish expression mechanism for farmers' interests. The current expression mechanism and means for farmers to express the needs for public services and public resources are extremely limited. Over time, it will undermine the legal foundation of the local governments especially the town governments that are faced with the public services at the grassroots level. Therefore, to give the local governments enough capacity to serve the rural, to eliminate the foundation of institution that the local officials are only concerned about the short-termed interests in the urban construction, and to improve farmers' expression ability for their interests, all these steps will help to promote the process of urban-rural integration.

\subsection{Innovation of the Cooperation Mechanism}

To change the urban-rural separated development patterns and promote the urban-rural integration, the behavior subjects, such as the governments, social organizations and citizens should cooperate with each other and work together on the existing institutions. The theory of path-dependence thinks that once the institution is locked, it still can be changed because the institution is always in flux. There are chances to break the path-dependence on every stage by means of the external effects. China's urban-rural integration currently is faced with important opportunities, which should be taken advantage of and carry it forward step by step. On one hand, with the development of China's economy, the improvement of productivity, the enhancement of overall economic strength and the more adequate income of financial, China already has a material basis for promoting the urban-rural integration. China has the condition to improve the quantity and quality of the basic public services in the rural areas on the basis of not reducing the urban residents' welfare, that is, to realize the "Pareto improvement" between the city and the countryside. On the other hand, as the market economy in China improves continuously, it is inevitable demanded to realize the free flow of production factors between the urban and the rural areas and market forces to promote the urban-rural integration are growing. In this case, the governments should play a dynamic role in the integration of social resources and promote the development of the urban-rural integration, and thus promote sound and rapid development of the national economy.

\section{Conclusion}

The process of urban-rural integration is influenced by the government concept of separated administration in the urban and the rural areas, the impact of the choice of the initial institution, the negative impact of the urban and the rural subject behavior. Therefore, innovation is needed in the concept of governance, institutional framework, motivation system and cooperation mechanism to break the path-dependence and to improve the level of integration between the rural and the urban areas, which will contribute to achieving better and faster development in China.

\section{References}

[1] Lan, H.T. (2005) The Institutional Analysis on the Evolution of the Urban-Rural Dual Structure in China. Macroeconomic Management, 3, 47-49.

[2] Li, Y.N. (2008) The Reform of the Rural-Urban Dualism. Journal of Peking University, 2, 5-11.

[3] Zhen, F. (1998) Discussion about the Theory and Planning of the Urban-Rural Integration. Urban Planning Review, 6, 28-31.

[4] Hong, Y.X. and Chen, W. (2003) Urbanizing and Integration of Urban and Rural Areas. Economic Theory and Business Management, 4, 5-11.

[5] Gu, Y.K. and Shao, F. (2003) Promoting the Reform of Urban-Rural Integration Comprehensively-The Fundamental Way of Solving the Issues Concerning Agriculture, Countryside and Farmers. Chinese Rural Economy, 1, 20-26.

[6] Liu, H.M. and Zhang, Z.J. (2012) The Analysis on the Influence Factors of China’s Urban-Rural Integration-A Gravity Model on the Basis of the Provincial Panel Data. Chinese Rural Economy, 8, 4-15. 
[7] Chen, X.H. and Zhao, H.J. (2007) The Motives and Consequence of the Urban-Rural Integration: From the Perspective of Institutional Innovation. Rural Economy, 8, 97-100.

[8] Zhu, Z.P. (2008) The Institutional Changes of the Urban-Rural Dualistic Structure and the Urban-Rural Integration. Soft Science, 6, 104-108.

[9] Zhang, Q. (2013) The Research and Exploration of China’s Urban-Rural Integration. Chinese Rural Economy, 1, 1523.

[10] North, D.C. (1920-2015) (2014) Institutions, Institutional Change and Economic Performance. Translated by Hang Xing, Shanghai People’s Publishing House, Shanghai.

[11] Xie, B.J. (2012) The Research of China’s Regional Integration: From the Perspective of Path-Dependence. Academic Research, 1, 44-48.

[12] Zhu, S.L. (2013) Integrated Development of Rural and Urban Areas in China. Beijing Publishing Press, Beijing.

[13] Wu, J.L. (1997) Where to Find Great Wisdom. Beijing Joint Publishing, Beijing.

[14] Wang, X.N. (2005) The Path-Dependence and Innovation of the Institutional Transition of the Rural Public Goods Supply. Chinese Public Administration, 7, 74-77.

[15] The Research Group of the Rural in the Development Research Center of the State Council (2014) From the Urban-Rural Dual Structure to Urban-Rural Integration-The Prominent Contradiction and the Future Trend of the Dual Mechanism in China. Management World, 9, 1-12.

[16] Li, Y.N. (2009) Advance toward Urban-Rural Integration: The Institutional Transition in the Urban and the Rural over the Past 60 Years. Journal of Peking University, 6, 5-19. 